\title{
CAMA
}

Centre for Applied Macroeconomic Analysis

\section{Inflation and monetary policy: What South African newspapers report in an era of policy transparency}

\section{CAMA Working Paper 48/2019 July 2019}

\section{Monique Reid}

Department of Economics, University of Stellenbosch, South Africa

\section{Zinette Bergman}

Department of Social Research and Methodology, University of Basel, Switzerland

\section{Stan Du Plessis}

University of Stellenbosch, South Africa

\section{Manfred Max Bergman}

Department of Social Research and Methodology, University of Basel, Switzerland

\section{Pierre L. Siklos}

Department of Economics, Wilfrid Laurier University

Balsillie School of International Affairs

Centre for Applied Macroeconomic Analysis, ANU 


\section{Abstract}

Inflation is a monetary policy outcome, but in the short to medium term, price and wage decisions are co-determined by the public and private sectors. Many central banks have adopted transparency as a strategic policy approach, whereby communication of monetary policy goals is used as a public anchor. While the central bank's strategy involves carefully crafted, deliberately simplified messages, most of the public tends to access inflation-related information through the media. In this paper, we examine South African newspaper articles to identify how inflation is presented in the media and the role of the media, through this presentation, in the process of shaping public opinion around inflation expectations. We do this in two ways. First, we examine how inflation is presented in the media and then we identify the various actors presented in the media, their positions on inflation, and how these relate to each other. The systematic analysis of the media's presentation of inflation allows us to identify some challenges to the central bank's communication strategy.

\section{Keywords}

inflation, inflation expectation, South African Reserve Bank, content configuration analysis, newspaper, media

\section{JEL Classification}

E31, E52, E58, E71, Z13

\section{Address for correspondence:}

(E) cama.admin@anu.edu.au

ISSN 2206-0332

The Centre for Applied Macroeconomic Analysis in the Crawford School of Public Policy has been established to build strong links between professional macroeconomists. It provides a forum for quality macroeconomic research and discussion of policy issues between academia, government and the private sector.

The Crawford School of Public Policy is the Australian National University's public policy school, serving and influencing Australia, Asia and the Pacific through advanced policy research, graduate and executive education, and policy impact. 


\title{
Inflation and monetary policy:
}

\section{What South African newspapers report in an era of policy transparency}

Monique Reid, Zinette Bergman, Stan Du Plessis, Manfred Max Bergman, and Pierre Siklos

\begin{abstract}
Inflation is a monetary policy outcome, but in the short to medium term, price and wage decisions are codetermined by the public and private sectors. Many central banks have adopted transparency as a strategic policy approach, whereby communication of monetary policy goals is used as a public anchor. While the central bank's strategy involves carefully crafted, deliberately simplified messages, most of the public tends to access inflation-related information through the media. In this paper, we examine South African newspaper articles to identify how inflation is presented in the media and the role of the media, through this presentation, in the process of shaping public opinion around inflation expectations. We do this in two ways. First, we examine how inflation is presented in the media and then we identify the various actors presented in the media, their positions on inflation, and how these relate to each other. The systematic analysis of the media's presentation of inflation allows us to identify some challenges to the central bank's communication strategy.
\end{abstract}

\section{Keywords:}

inflation, inflation expectation, South African Reserve Bank, content configuration analysis, newspaper, media

\section{JEL code:}

E31, E52, E58, E71, Z13

\begin{abstract}
Monique Reid (corresponding author) is Associate Professor in the Department of Economics, University of Stellenbosch, South Africa. Zinette Bergman is a researcher in the Department of Social Research and Methodology, University of Basel, Switzerland. Stan du Plessis is Professor and Chief Operating Officer of the University of Stellenbosch, South Africa. Manfred Max Bergman is Professor in the Department of Social Research and Methodology, University of Basel, Switzerland. Pierre Siklos is Professor in the Department of Economics, Wilfrid Laurier University and Balsillie School of International Affairs, Canada and Research Associate at the Centre for Applied Macroeconomic Analysis (CAMA). This work was supported by the National Research Foundation in South Africa (grant number 93520). The National Research Foundation had no role in the study design; collection, analysis and interpretation of data; in the writing of the report; or in the decision to submit the article for publication.
\end{abstract}


Inflation and monetary policy:

What South African newspapers report in an era of policy transparency

'They [the South African Reserve Bank] had to do something to convince the public that they won't let inflation run away...'

(Mail \& Guardian, 17-07-2014, parentheses added)

1. Introduction

The success of monetary policy may be judged relative to its appropriate goals. They are: price stability, financial stability, and prudent financial support for government (Goodhart, 2010). While financial stability has risen in importance as a policy goal since the international financial crisis of 2008-9, price stability and macro-economic stability more generally remain central goals of monetary policy.

Inflation, the process by which money loses its value over time, is a monetary policy outcome. But the process of inflation involves decisions about prices and wages in the public and private sectors that co-determine how it will evolve over the short to medium term. An important lesson of monetary policy since the 1980s is that the goal of low and stable inflation can be achieved more effectively if price and wage decisions are co-ordinated with the actions of the central bank. Since the decisions of the public and private sectors are market-based, this coordination cannot occur hierarchically, although the central bank's commitment to low and stable inflation does contribute to the creation of a credible focal point for market decisions. An additional complication is that, to some extent, price and wage decisions are forward 
looking, which implies that the focal point is also about expected future price and wage developments. The central bank’s task is to persuade market decision makers to coordinate their price expectations with the goals of the central bank.

The involvement of multiple forward-looking decision makers in achieving the central banks' monetary policy goals has highlighted the importance of adopting a strategic policy approach aimed at communicating effectively. This communication strategy is essentially an attempt to convey information as well as an act of persuasion, and the implementation thereof has contributed to unprecedented transparency in the conduct of monetary policy. The aim of transparency is to increase the credibility and predictably of the central bank's actions in the eyes of the public in order to encourage them to anchor their inflation expectations to the target. The literature on central bank communication has focused on evaluating the effectiveness of these strategies, raising questions about implementation and outcomes.

In 2014, for example, the South African Reserve Bank (SARB), explicitly charged with maintaining price stability defined in terms of a target band for CPI inflation ranging between 3 to $6 \%$, faced the challenge of high inflation and a weak and deteriorating economy. Inflation breached the upper limit of the target band in April, and the SARB forecasted in its June Monetary Policy Review that inflation would remain above the band until the second quarter of 2015 (see Figure 1). This was accompanied by disappointing economic growth which according to the SARB forecast at the time would not improve significantly over the forecast horizon (see Figure 2). However, assisted by lower oil and food prices, inflation (as measured by the consumer price index) peaked sooner than expected and decreased to within the band in September and October 2014, although the SARB had predicted it to remain above the band for the rest of the forecast horizon. With Gill Marcus as Governor of the SARB until 8 November 2014, and Lesetja Kganyago thereafter, the repurchase rate was increased gradually 
by 75 basis points throughout the year, constituting the first rate hiking cycle in over 5 years. Despite these positive developments and the fact that interest rates remained at low levels (see Figure 3), inflation expectations and core inflation remained stubbornly high, growth continued to disappoint, and the SARB estimated that potential growth had deteriorated further during the year.

Figure 1: Targeted Inflation Forecast

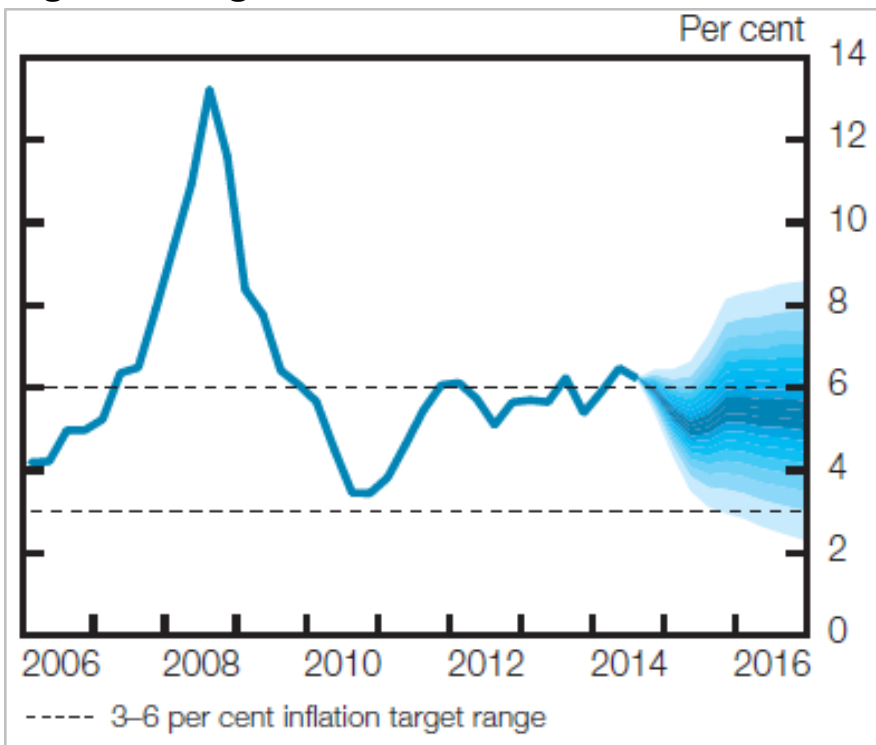

* CPIX for metropolitan and other urban areas until the end of 2008; CPI for all urban areas thereafter

Source: SARB (2014b)

Figure 2: Real GDP Growth Forecast

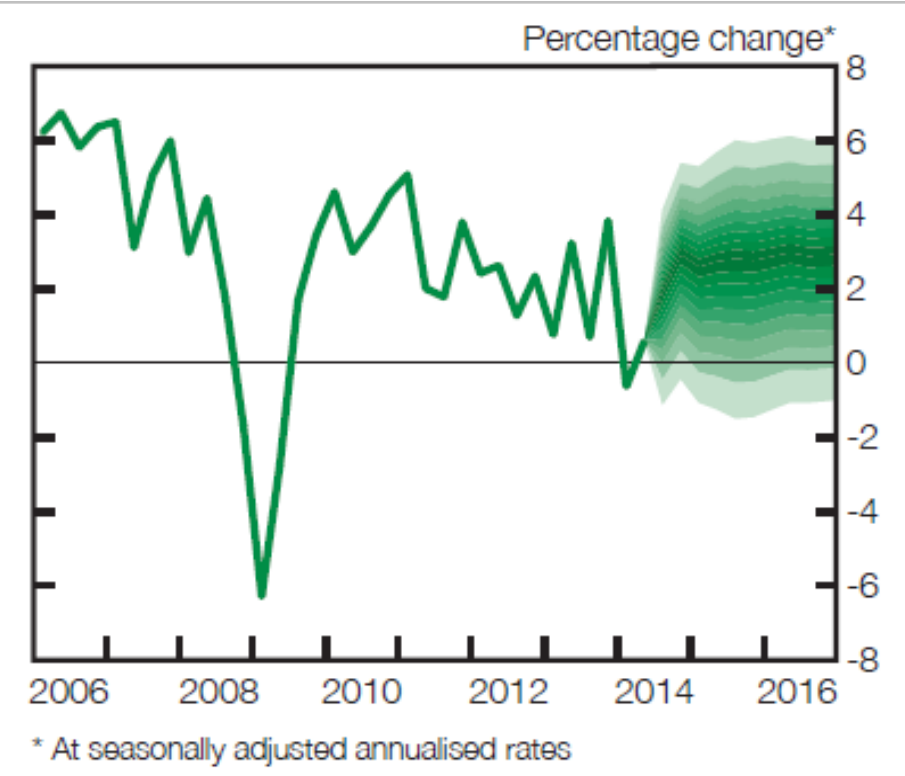


Source: SARB (2014b)

Figure 3: Monetary policy and the prime lending rate

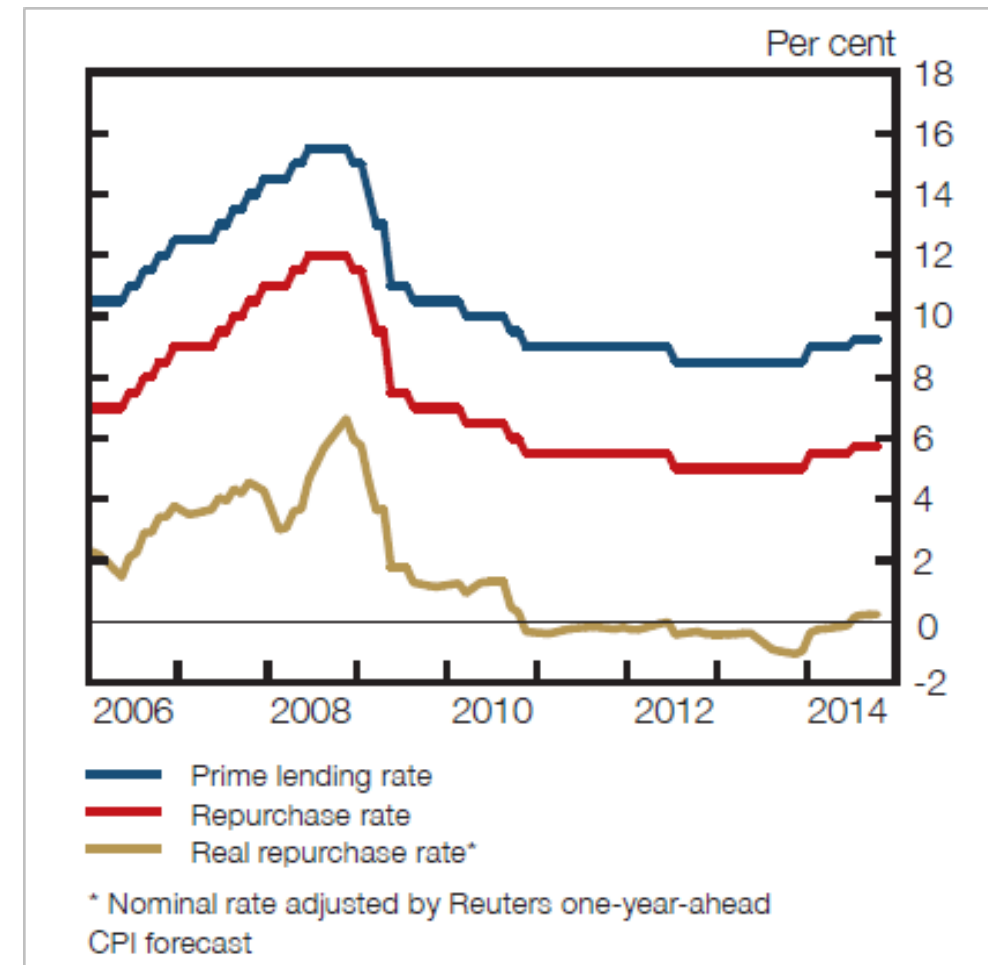

Source: SARB (2014a)

In this article, we examine 101 articles from 14 regional and national English-language newspapers published in SA in 2014 to identify how inflation expectations are presented in the media and how, through this presentation, public opinion around inflation expectations is being shaped. Specifically, our objective is to explore the role of the media in society and its connection to the process of anchoring inflation expectations. Following a more inductive approach, we do not identify a narrow hypothesis about how inflation expectations are formed or a study a particular contribution of the media to this process. Instead, we adopt content configuration analysis in an exploratory manner, with the aim of describing the kind of messages about inflation and inflation expectations presented in the South African media. This does allow us to comment on the kind of role the media was playing in 2014 in South Africa, relative to the one that monetary economic theory would suggest. 
We do this in two ways. First, we examine how inflation is presented in the media - what it is, what causes it, and what the consequences are. We then identify the actors presented in the media, their positions on inflation, and how these relate to each other. By systematizing how inflation is presented in the media, we aim to highlight some of the challenges that monetary policy makers face. While theory suggests that monetary policy is strategic in nature, it follows that transparency should be used to anchor inflation expectations of the public. Yet, we know very little about the actual messages emanating from the media to the public.

The rest of the paper is organized as follows. We review the economics literature as it pertains to the spread of transparency and the increased emphasis on communication by central banks. We then bring in the media in its role as an intermediary that competes for the public's attention at the same time as the central bank also seeks to communicate directly with the public. We then briefly outline the methodological approach used to analyse media content about the SARB's role and objectives before discussing our findings. Implications are then drawn prior to a concluding section about how central bank communication may be impacted by our findings as well directions for future research.

\section{Theoretical background}

2.1 Central banks and the evolution of strategic monetary policy

During the late 1960s and 1970s (led by Friedman (1968) and Lucas (1976)) the role of expectations in monetary models and theory, as well as the practice of monetary policy, became broadly accepted. Monetary economists argued that the primary objective of a central bank - achieving price stability (low and stable inflation) - was more efficiently achieved when the price and wage setting decisions of the public were broadly in line with that of the central 
bank itself. In this sense, monetary policy is strategic in nature (Kydland and Prescott,1977) and there is a strong incentive for monetary authorities to offer a credible commitment to a particular pattern of policy behaviour (Shelling, 1960), so that the public will choose to align its prise setting behaviour with the central bank's target. Crucially, economic policy takes place in a dynamic setting and members of the public are not passive participants in the economy because their welfare is influenced by these policies.

In order to manage private sector expectations, monetary policy institutions are designed to provide clarity to the public about the incentives faced by the central bank. Specifically, the strategy by modern central banks is typically to use a nominal anchor to provide "a constraint on the value of domestic money" or, more broadly, to provide "a constraint on discretionary policy” (Mishkin, 1999:1) ${ }^{1}$. In line with the concept of anticipatory self-command (Shelling, 1960), central banks began to limit their own discretion in order to communicate to the public that the central bank was committed to low and stable inflation.

Inflation targeting and greater transparency about monetary policy are two of the main ways in which monetary policy institutions provided clarity on the incentives faced by central banks over the past 3 to 4 decades. Through the adoption of inflation targeting, a central bank limits its ability to use discretion by publically committing to a numerical target for inflation ${ }^{2}$. This

\footnotetext{
${ }^{1}$ In societies where decisions interact dynamically as described above, inflation and inflation expectations have not been successfully stabilised at the low levels pursued by central banks without these authorities committing to some form of nominal anchor or to some institutional arrangement that limits the central bank's policy discretion in a strategic manner (Walsh, 2003).

${ }^{2}$ Inflation targeting has become the most durable nominal anchor for monetary policy in the post-War era (Rose, 2007). While the local application of this framework differs between countries, the following features are common to most applications: (1) The announcement of an explicit target for inflation over a certain (usually medium) horizon; (2) The absence of alternative nominal anchors; (3) The use of this explicit target in a strategic approach to monetary policy, which includes (i) A forecasting strategy for inflation, the output-gap, and other relevant variables, and (ii) A communication strategy that implies substantial transparency for the monetary policy process.
} 
clarifies the incentives faced by the central bank and makes its future policy setting behaviour more predictable. Consequently, central banks have generally become more transparent (especially since the 1990s), which Mishkin (1999) argues is essential to providing a credible nominal anchor.

Cukierman (2009:3) defines transparency as “a state in which the bank fully and immediately transmits to the public all its private information about the economy, about its objectives and about the internal procedures that underlie the bank’s policy decisions.” Earlier, the Bundesbank, the forerunner of the current European Central Bank, described transparency in the following manner:

Transparency here plays the part of self-imposed commitment: by disclosing the basis of the policy decisions, the central bank enables the general public to assess their adequacy and impose a sanction, if appropriate (Bundesbank, 2000:17).

While it is generally acknowledged that transparency has its limits (Cukierman, 2009) ${ }^{3}$ and there are disagreements on the net benefits of central bank transparency (Eijffinger and van der Cruijsen, 2010), many authors highlight how the clarity of communication outweighs the mere achievement of transparency (Siklos, 2003; Winkler, 2002). Recognising that a central bank communicates with a heterogeneous audience, Eijffinger and van der Cruijsen (2010:293) recommend that the "best communication strategy is likely to depend on the

\footnotetext{
${ }^{3}$ Cukierman (2009) points out that the level of transparency with respect to the structure of the economy is hampered by the banks' limited knowledge about the structure of the economy. Furthermore, central banks' transparency about the relative weight they place on the output and inflation gaps, as well as the shape of the losses from these two, is constrained by the fact that in practice monetary policy decisions are made by committees, whose members may view this differently. As Swank and Visser (2007), and Siebert (2006) point out, committees of experts face their own challenges as there is pressure either to conform or to free-ride. Moreover, the level of diversity can be affected according to whether the background and training of the committee members differs. Also, see Maier (2010) for empirical evidence.
} 
recipient”. In a 2008 survey paper, Blinder et al. (2008) pointed out that the empirical evidence about central bank transparency had progressed more quickly than theory. According to these authors, acknowledging that a central bank’s audience is heterogeneous and that a large part of this audience does not access this communication in its original form offers the potential to enrich economic theory.

2.2 The role of the media in strategic monetary policy

Surprisingly, these notions have not been explored extensively in monetary policy research. The monetary economics literature has, to a limited extent, acknowledged the heterogeneity of a central bank's audience. Blinder and Wyplosz (2004) divided the audience broadly into the financial markets (financially literate and well informed about monetary policy) and the inattentive public. Others have expanded this concept of the rationally inattentive public (Cukierman, 2009) and considered the implications of their behaviour, as distinct from those of the more informed analysts, for macro modelling (Mankiw and and Reis, 2007; Sims, 2010). We acknowledge that the rationally attentive public is a heterogeneous group, so this concept in itself is a simplification of reality.

There is also growing evidence from the media economics literature about media bias (Gentzkow and Shapiro, 2010) and the effects of media exposure on a range of social and economic decisions (Della Vigna and La Ferrara, 2016), including voting behaviour (Della Vigna and Kaplan, 2007), children's education, and health. Evidence on the effects of the media on voting behaviour are particularly relevant to this paper, as monetary policy is a political act, being part of a macroeconomic policy mix, even if central bankers are not political policy makers. 
However, most of the literature on central bank communication has focused on the quantity and quality of the original communication sent by central banks, emphasising the need to be simple (Mishkin, 2004), clear (Bulír, et al. (2013a); Bulír, et al. (2013b); Siklos (2003); Winkler (2002)) and predictable (including Ehrmann and Fratzscher (2007); Poole and Rasche (2003)), or evaluating how various measures of inflation expectations move shortly after communication is released (Gürkaynack, et al. (2006); Gürkaynack, et al. (2005)).

While the value of these particular features of central bank communication is not disputed, we extend the debate by emphasizing three additional dimensions. First, most members of the public do not receive the central bank's communication in its original form. Instead, they access information relating to monetary policy, inflation, and the central bank from the media. Second, the media is not a passive conduit of central bank communication, and news agencies expend considerable resources to gather, condense, interpret, and present information provided by central banks. In contrast to the carefully crafted, simplified messages from the central bank, the message the public tends to receive is a complex, collated mediation from multiple sources. Finally, the management of inflation expectations, while a primary objective of the central bank, takes place on an independent media platform. This is acceptable as long as we assume that journalists specifically and the media more generally tend to represent external events in an unadulterated manner. As Reese and Shoemaker (2016: 392) pointed out, we often either believe or demand that media content is "a true representation of events, people, or ideas, [which] is often treated as an implicitly true indicator of social reality.” This raises important questions about the role of the media in society and its connection to the process of anchoring inflation expectations.

Sociological approaches to the media's role can be divided into four types: The traditionalist approach assumes that the media is the primary platform through which societal ideas and 
values are communicated. It places society at the center of the communication landscape and suggests that media content provides a way to 'measure the cultural temperature of a society' (Weber, 1910, 2001). Grounded in the Chicago School and taken up by scholars such as Robert Park, media studies following this tradition investigate public opinion via community-based case studies and participant observation (Reese and Shoemaker, 2016). From this perspective, the media represents reflections on inflation expectations in society. Accordingly, a study of the media content on inflation may be used to identify and systematize the range of inflation issues most salient to the public, providing an indication of public sentiment.

Functionalist approach: The post-world War II era ushered in mass consumerism and a mass media industry built on the marketing model of advertising revenue (Reese, 2009). Along these lines, Columbia University’s functionalist approach emphasizes the "short-term effects, variable-analytic, [and] social psychology perspective” (Reese \& Shoemaker, 2016: 395) of news reporting. Instead of viewing the media as a reflection of societal norms and concerns, the role of the media is understood to serve strategic interests (Gitlin, 1978; Reese \& Ballinger, 2001). This focus leads to a preoccupation with reception studies to better understand the myriad of ways audiences respond to different types of messages. The key assumption of this input-output model is that the right message elicits a desired response, giving rise to the Propaganda Model (e.g. Herman and Chomsky, 1988). From a functionalist perspective, it is possible for the central bank to use the media as a tool to plant strategic messages or to educate journalists on how to anchor in the public messages on inflation and inflation expectations in line with the bank’s policy agenda.

Hybrid approaches: In his seminal work Deciding what's news, Herbert Gans (1970) proposed that the media could not be understood apart from the organizational context within which it was produced because "[n]ews is said to reflect the hierarchies of society and nation, just as 
journalists are thought to follow the rules of their organizational setting's structure” (Reese, 2009: 283). Gans’ work revealed that bureaucratic factors and economic constraints create news processing that is obsessed with developing marketable products for audiences, while frequently having little concern for the audiences themselves (Gans, 1970). He proposed that "[t]he news equation [was] based on efficiency and power, meaning that news workers must allocate scarce resources in producing their product, with due respect to the power structure within which they operate” (1970: 283). Accordingly, news content serves the interests of a powerful elite, or the economic, time, or power constraints inherent in the media industry. From this perspective, central banks have little to no influence on media messages because the news equation embedded in the media machine sets the priorities of what counts as news or whose interests it serves; inflation expectations are defined the media's self-serving priorities and interests instead.

Modern approaches: Gans (1970: 298) also proposed a multi-perspectival approach to news in which "one of the journalists' prime functions is to manage, with others, the symbolic arena, the public stage on which nation, societal, and other messages are made available to everyone who can become an audience member.” Rooted in political science, the modern approach to media introduces concepts such as “networked institutions” (Anderson, Bell, \& Shirkey, 2012) or “networked journalism” (Jarvis, 2006) to define the media’s function as a significant political actor in a larger political and societal network (Ryfe, 2006). This conception captures the complex evolution of mediatization into "a distinctive stage in mass democracies in which political processes have grown more or less dependent on the mass media and shaped themselves accordingly”(Reese \& Shoemaker, 2016: 403). According to Reese and Shoemaker (2016: 402), this interdependent process is characterized by continuous negotiations of power in which boundaries are constantly renegotiated as "power flows not only from the state to the media but the other way around in a process of mutual adaptation.” 
The modern perspective casts central banks as one of many important political actors or stakeholders, which, interdependently, negotiate control over 'inflation messages' as they attempt to set agendas on inflation expectations via communication strategies and media platforms.

While the four approaches reflect the chronological development of understanding the role of the media, they also highlight the changing roles, responsibilities, and expectations of stakeholders who create, shape, and consume news content. The role the media plays as the mediator of the SARB's monetary policy becomes a crucial link to the SARB's ambitions to utilize transparency to anchor inflation expectations in the public domain. Each of these approaches imply significantly different interpretations of the relationship between the central bank and the media, the role the media plays in presenting inflation, and the consequences this has on anchoring inflation expectations. In this article, we investigate the nature of the message on inflation and inflation expectation in relation to the four approaches, and what consequences the messaging has on SARB's communication strategy.

\section{Outline of the Data and Methodology}

101 articles were selected from 14 regional and national English-language newspapers published in SA. These articles were downloaded from two online media platforms, the Mail and Guardian (www.mg.co.za) and the Independent News and Media Database (www.iol.co.za). The selection criteria were a publication date between 1 January and 31 December 2014, and the main subject matter pertaining to either inflation or the SARB. Data was analysed using Content Configuration Analysis (CCA; Bergman (2010); Bergman and Bergman (2011)). CCA is a systematic analysis method for non-numeric data. Related to qualitative content and thematic analyses, CCA has several unique characteristics (Bergman 
(2010); Bergman and Bergman (2011)). One of the major strengths of this method is that it can be adapted to researcher or research needs. In this analysis, for example, we conducted an inductive, exploratory analysis to systematise the media representations of inflation and the SARB in the South African media. This means that themes were developed in situ, based on an exploration of the dimensions embedded in the newspaper narratives as opposed to deciding a priori on specific thematic criteria and then coding the data accordingly (quasi-deductive, top-down analysis). Excerpts from a wide variety of sources are used to paint a picture of how the media portrays and interprets inflation and the SARB's performance.

\section{Results}

In this analysis, we were interested in the dimensions of monetary policy and how they are portrayed in the media. We analysed systematically the media representation of inflation and then examined the various actor groups used in the media to construct these representations of inflation.

\subsection{Results 1: Representations of inflation}

\subsubsection{Definitions of inflation}

An analysis of how inflation is defined in the South African media revealed three interesting features: The first relates to the range of terms used to discuss inflation; the second, to how rarely the concept of inflation is defined at all; and the third, to a focus on rising prices of selected consumer goods and services as synonymous with the central bank's concept of inflation. 
We found more than 30 inflation-related concepts. These included various indices, which act as proxies for inflation ${ }^{4}$, concepts related to the measurement of indices ${ }^{5}$, and concepts referring to the broader inflation environment ${ }^{6}$. A variety of inflation rates ${ }^{7}$ are also reported, as well as a range of inflation forecasting dimensions ${ }^{8}$. Despite the profusion of concepts, inflation is rarely explicitly defined, and the similarities or differences between the various inflation concepts used in media reports are not discussed.

The only explicit definition of inflation found during the analysis is that of core inflation. ${ }^{9}$ This definition seems to be more-or-less standardised and it appears nearly verbatim across various newspapers throughout 2014 in the following manner:

Core inflation - which excludes food, non-alcoholic beverages, petrol and electricity - rose to 5.8\% in August, its highest level in four years. (10-20-MG-Economic)

Beyond this explicit definition of core inflation, no other definition of inflation was identified. Instead, inflation is most frequently defined implicitly by referencing the price increases, often emphasising how it negatively impacts the lives of consumers, especially the poor. ${ }^{10}$ Here are two examples:

\footnotetext{
${ }^{4}$ For example, consumer price inflation and core inflation.

${ }^{5}$ For example, inflation basket and inflation data.

${ }^{6}$ For example, inflation environment and US inflation.

${ }^{7}$ For example, the consumer inflation rate, core inflation rate, personal inflation rate, and CPI annual inflation rate.

${ }^{8}$ For example, the inflation trajectory, inflation pressures, and inflation risk.

${ }^{9}$ This definition of core inflation does not define inflation. It merely distinguishes it from headline inflation.

${ }^{10}$ For example, personal inflation, food price inflation, consumer inflation, car inflation, and household inflation.
} 
Inflation accelerated to 5.4\% from 5.3\% in November, the Pretoria-based statistics office said. The median estimate of 23 economists in a Bloomberg survey was 5.6\%. Prices rose $0.3 \%$ in the month.

(01-22-MG-Inflation)

By contrast, the price of clothing and footwear is estimated to have increased by 3.6 percent and 3 percent respectively. The food basket was also up 3 percent. (02-17-IOL-Monetary)

Inflation concepts and definitions in the print media are reported in two distinct ways: They are either associated with the increase of prices although a clear definition of what inflation is or how it works is absent from such news reports. Inflation, as presented in the media, is an amorphous concept, which threatens the wellbeing of the population, especially the poor. Alternatively, it is explicitly defined as core inflation, removed from the daily lives of consumers and unrelated to the cost of food, beverages, clothing, petrol, or electricity.

Thus, it is either an undefined, amorphous concept with a direct negative impact on the public, or a technical economic construct ${ }^{11}$. To better understand how this dichotomy is represented in the media, we analysed the causes and consequences associated with inflation as reported in the media.

4.1.2 The reported causes and consequences of inflation

${ }^{11}$ Because the media is not trying to reconcile these different representations of what inflation is, there is no recognition that inflation is a process. The consequences of inflation expectations is also conspicuously absent from media discourse on inflation and the SARB. Instead we find strikingly different 'versions' of the inflation story embedded in the media. 
The range of causes of inflation as reported in the media can be divided into two types, namely local and global causes, with the local more frequently reported. Of the local causes of inflation, weak economic growth is most often reported in conjunction with, for example, increases in prices, and exchange rate movements. Also associated with causes of inflation, sometimes referred to as 'the deteriorating fundamentals', are unions, strikes and wage negotiations, political pressure, high government debt, and high unemployment. Here are some examples:

The MPC remains concerned about weak growth, widening output gap and the negative employment outlook. ... These [deteriorating domestic fundamentals] included the negative GDP (Gross Domestic Product) growth rate, the adverse reports from the ratings agencies, and the protracted nature of the platinum and metal workers strikes.

(07-17-MG-Rising)

Much of the outlook is "dependent on the behaviour of the currency, domestic food prices and the extent to which local retailers start to pass on price increases more aggressively to consumers," he said. (07-23-IOL-Inflation)

The global causes of inflation mentioned in the media relate to the effects of financial market volatility, slowing demand, and the lasting consequences of the global economic and financial recession. These issues are most often associated with either the United States or emerging economies. Newspaper articles report how changes in the United States or emerging economies create pressure on the SARB to make corresponding policy changes. This reveals a tension between global trends, where external pressures dictate inflation policy on the SARB, 
and local forces, where the SARB is attributed with a greater degree of freedom. Here some examples:

Likely interest rate increases in the United States would require corresponding policy shifts in South Africa, Kganyago said in a speech prepared for delivery at an investor conference in Cape Town. (09-30-IOL-Kganyago)

While the normalisation of interest rates in the US suggests South Africa should also raise borrowing costs, doing so carries the risk of weakening the economy, according to Mminele. Africa's second-biggest economy is constrained by labor strikes, power-supply shortages, slowing consumer demand and the rising cost of inputs, he said. (11-28-IOL-SARB)

The South African exchange rate connects global and local contexts. Media reports often identify the Rand as one of the primary risks to inflation locally because of the pressure it puts on consumer prices. The Rand is described as 'fragile', 'weak', 'volatile', 'swooning', or 'drastically sliding further'. Globally, the US Dollar and its exchange rate with the Rand is said to place upward pressure on inflation. Thus, the exchange rate is presented as being both volatile and as having an unpredictable relationship with inflation. Here are some examples of the Rand being subjected to both local and global references:

The Rand's 22\% slump against the Dollar since the beginning of last year, the worst performance among 16 major currencies tracked by Bloomberg, is adding to pressure on inflation and threatening the central bank’s 3\% to 6\% target.

(01-22-MG-Inflation) 
A weakening rand has been a major cause of higher prices, hitting a string of five-year lows at the beginning of the year when the central bank hiked the repo rate by 50 basis points to 5.5 percent.

(06-26-IOL-SARB)

In media reports, prices often appear interchangeably as both a cause and a consequence of inflation. Given that inflation is a process, whereby prices in general rise, this is not surprising. However, the fact that the reports never explain that inflation is a process and rarely discuss the role of inflation expectations, can make this look like a conundrum. In this following example, higher international prices (the cause) lead to higher local prices (the consequence):

Econometrix said this was the fifth successive month in which CPI had increased. It said the increase was particularly marked in the case of durable goods, illustrating the fact that the pass-through from rising imported input costs had started exerting a significant upward push on inflation.

(22-05-IOL-Inflation)

The media predominantly emphasises the increase of prices, whether reported as a consequence, a cause, or as a definition of inflation. This leads to circularities whereby prices rise, which leads to rising prices. Although increasing prices are by far the most common example of this, other circularities resulting from an overlap between causes and consequences of inflation relate to interest rates, the exchange rate, economic growth, and the impact on investors and investments.

An analysis of what inflation is and what the causes and consequences of inflation are reveals several interesting characteristics. First, a plethora of inflation-related concepts are used in media reports. The presentation of these concepts is surprisingly untechnical in that a wide 
range of terms are used. Second, there are multiple overlaps, circularities, and tautologies observable between the causes and consequences of inflation. Interestingly, the lack of technical explanations in conjunction with an overuse of nomenclature and an undifferentiated overlapping of cause and effect helps to create a representation of inflation, which seems simultaneously indiscernible, omnipresent, and overwhelming. Finally, a strong focus on the impact of inflation on consumers dominates many of these inflation dimensions. This is accompanied by a distinct emotive argument that underpins most media reports. By continuously emphasizing typically volatile price increases, this argument plays on consumers' fear of steadily rising prices, a point we will return to below.

4.2 Results 2: Voices shaping inflation and inflation expectations in the media

The complex intersection and overlapping of terms evident in the previous analysis is due in part to the multiple stakeholder perspectives used to formulate the representations of inflation in the media. Our next analysis consisted of an exploration of the views of different actor groups presented in the media and how media narratives position these actors in relation to each other. We begin this section by presenting the findings associated with the two primary actor groups, which dominate most media narratives: the SARB, external financial experts and consultants. We then examine how these two actor groups are connected to each other via a third actor, namely consumers. Finally, we recognise that the media itself represents the fourth actor in that it actively formulates positions in relation to inflation and inflation expectations. The media is not a passive conduit of communication from the SARB but, instead, sets the agenda in the newspaper articles and makes decisions about which opinions to include and how to present these. 


\subsubsection{South African Reserve Bank and the anchoring of inflation expectations}

There are three characteristics that define the representation of the SARB in the media. First is the role of the SARB as a commentator on the global and local risks and opportunities facing the South African economy in general and inflation in particular; second is the description of the central responsibilities of the SARB as mentioned in the media; and third, the SARB's position on monetary policy in SA, including their inflation forecasts. Media representation of the SARB commenting on global and local economic issues, for example, highlight the range and complexity of issues impacting the South African economy, inflation, and monetary policy, and how the central bank needs to carefully consider these during its policy deliberations or when developing inflation forecasts. Some of the issues mentioned include, internationally, a deteriorating global environment in the aftermath of the global financial crisis, slow growth in Europe and China, as well as policy shifts in the United States and other emerging economies; and nationally, issues such as lowered productivity, rising costs, labour unrest, energy insecurity, government debt, rising unemployment, the weak Rand, and weak economic growth. Responding to how these issues impact on inflation, the SARB is often portrayed as needing to 'control', 'tame', or 'conquer' inflation, which tends 'to be uncomfortably high' so that it does not 'increase', 'run away', or 'endanger price stability'. Here are some examples:

In her monetary policy committee statement in March, Gill Marcus, the governor of the Reserve Bank, said: "While the most recent inflation forecasts suggest marginal improvements in the medium term, upside risks to the inflation outlook persist despite the recent appreciation of the rand, which remains vulnerable to shifts in global risk sentiment and adverse domestic developments. Together with the 
downside risks to growth, this continues to pose a dilemma for monetary policy.” (22-05-IOL-Inflation)

The inflation data “will most certainly continue to highlight the Reserve Bank’s current dilemma of managing an uncomfortable domestic inflation environment amid a weakening economic backdrop.”

(06-18-IOL-Consumer)

In media narratives, keeping inflation low is often considered to be the main role of the SARB. Media narratives mention how the SARB explicitly emphasises that its central objectives are limited to inflation targeting and anchoring inflation expectations, while fostering economic growth and stabilizing the South African Rand fall outside their mandate. Here some excerpts:

While growth is a concern, "the primary responsibility of the bank is to keep inflation under control and ensure that inflation expectations remain well anchored," Marcus said.

(02-03-IOL-Traders)

Marcus warned that monetary policy should not be seen as the growth engine of the economy and the sources of the below par growth performance are largely outside the realms of monetary policy. (07-17-MG-Rising) 
South Africa’s rate increase wasn't aimed at supporting the rand, though the currency's weakness is the primary risk to inflation, Marcus said.

(02-03-IOL-Traders)

Finally, in terms of monetary policy in general and inflation targeting specifically, the media portrays the SARB as confident and in control, despite the many and varied threats mentioned earlier. According to this position, monetary policy in SA remains accommodative and, despite forecasts that the inflation rate would be above the target range for most of 2014, the central bank seems unconcerned since they expect it to return to within the target range during 2015. Here some examples:

The Reserve Bank kept its benchmark repurchase rate unchanged at 5.5\% last month even as it forecast inflation would stay outside the 3\% to 6\% target band until the second quarter of next year.

(06-18-MG-Inflation)

As indicated at its last meeting, the committee continues to expect inflation to breach the upper end of the target range in the second quarter of 2014, and to return to within the target range in the second quarter of 2015, when it is expected to measure $5.9 \%$.

(03-27-MG-Gill) 


\subsubsection{Financial experts}

The other dominant actor group present in media reports on inflation consists of a wide range of financial experts. ${ }^{12}$ This actor group is used for both forward- and backward-looking commentary. In the first instance, they predict future inflation trends and corresponding reactions from the SARB. In terms of inflation rates, for example, financial experts reported in the media tend to predict inflation rates which are higher than those forecasted by the SARB during the sample period studied here. According to them, inflation would continue to edge up and remain above the SARB's target range. Although a consensus in terms of the degree and kind of changes in inflation seems to be lacking, most analysts do concur that inflation, during 2014, was high and distressingly moving upward. Here are some examples:

BER said whereas business people see inflation remaining at 6.2 percent in 2016, analysts and trade unions expect it to edge up 0.1 percentage point to 5.5 percent and 6.0 percent respectively.

(12-11-IOL-SA)

Our baseline scenario is that rates will be kept on hold at this meeting, but that the risk of further rises as inflation moves above the 6 percent upper target limit is

\footnotetext{
12 These include market watchers, such as investors, strategists, asset managers, economists, market researchers, analysts, and financial advisors from a wide range of local and global private corporations. Also cited are banks, including Investec, the IMF, Nedbank, Old Mutual, Bidvest Bank, and Standard Bank, as well as several research units such as Statistics SA, Econometrix, and the Bureau for Economic Research (BER) at Stellenbosch University. Less prominent are reported positions of various individuals from the business sector, such as presidents, chief executives, and heads of retail, sales, and distribution units of large corporations. Finally, a group of anonymous economists, frequently surveyed by Bloomberg, also comment on inflation in the media. Interestingly, it is never stated who these economists are or whom they represent, and this group can vary from one survey to the next, consisting of between 12 and 30 economists.
} 
significant,” Nedbank said in an e-mailed note to clients before the release of the data. Nedbank had forecast inflation would accelerate to 6.2 percent.

(05-21-IOL-Consumer)

Another forward-looking dimension presented in media narratives focuses on when and why the SARB should respond to inflation. These narratives primarily emphasise the importance of economic growth and the SARB's role in supporting it. Often implied in these positions is that economic growth stands in opposition to inflation and should be one of the fundamental drivers of monetary policy. Here are some excerpts:

Economists are divided over whether South African Reserve Bank Governor Gill Marcus will act to counter above-target inflation, or support weak consumer spending and sputtering economic growth.

(07-16-MG-Economists)

"The Reserve Bank would be reluctant to choke off the little growth that is left in the economy," Abbas Ameli-Renani, a London-based emerging-markets strategist at the lender, said in an email.

(02-19-MG-Rand)

A second focal point frequently mentioned in the media relates to the SARB's responsibility in supporting the Rand. There are instances in media narratives when, according to these analysts, Rand vulnerability may or should override weak economic growth and inflationary pressures to become the main concern guiding the SARB's actions. Here some examples: 
“They have changed their tune,” Schoeman said by phone on January 31. “They have always have been a bank that targets inflation expectations, but now they are far more cognisant of the currency.”

(02-03-IOL-Traders)

Those concerns [slower global demand and mining strikes] are being overtaken by a weaker rand that's fuelling inflation and threatening the bank's 3\% to $6 \%$ target.

(01-29-MG-South)

Finally, in terms of backward looking commentary, many examples from media narratives illustrate how financial experts during this period were critical of the actions, priorities, and effectiveness of the SARB as these final excerpts show:

That the economy is as weak as it is indicates that interest rates should have been significantly lower than they have been, and should be falling, rather than rising, given the deteriorating state of the economy. Targeting inflation when prices are rising for supply-side rather than demand-side reasons makes little economic sense.

(02-17-IOL-Monetary)

Inflation fears were behind the SA Reserve Bank's (SARB) decision to raise the repo rate to 5.5 percent, Investec said on Wednesday. "In contrast to market expectations, the SARB opted to raise the benchmark repo rate by 50 basis points,” economist Kamilla Kaplan said in a statement. (01-29-IOL-Inflation) 
From the above we can see how even experts' views about inflation and the roles and responsibilities of the SARB can differ significantly from one actor group to the next. While media reports of the SARB's position on inflation rates seem to emphasise that inflation is under control and only temporarily above target, the position of financial analysts lacks this temporality and creates the impression that inflation is likely to remain high. More striking is how much the perceived responsibilities of the SARB deviate between these actor groups. While the SARB is reportedly focused on inflation and inflation expectations (and not economic growth or the Rand), the media presents the view that at least some financial experts believe that the SARB should also consider economic growth and the exchange rate. This can create the impression that these two actor groups are in opposition to each other. We must emphasise that these are the positions of the actor groups as represented by the media, which the actors themselves could potentially argue are not an accurate representation.

\subsubsection{Consumers: The victims of inflation and poor economic growth}

At the point where these two contrasting representations meet we return to one of the central findings of the first analysis - the way in which media narratives revolve around the impact of inflation on consumers. The third actor present in the media is by far the least developed. Instead, the public, portrayed primarily as consumers, are the victims of the consequences of high inflation and continuous price hikes. Although many of the excerpts we have presented throughout this article have illustrated this trend well, here are some more examples:

Food prices, which account for 14\% of the inflation basket, rose 3.5\% in December from a year ago, down from 3.8\% in November, Statistics South Africa said. It declined $0.1 \%$ in the month. "This is possibly one of the last positive effects from 
food prices as the sharp increases in corn prices and the weakening of the rand will start to show," Kruger said.

(01-22-MG-Inflation)

Your single biggest threat to retiring financially secure is inflation - both preretirement and in retirement," he says.

(04-13-IOL-Investing)

It is from the perspective of consumers where the disconnect between the SARB and financial experts plays out. Media narratives portray a central bank that, although threatened by significant international and local challenges, seems unconcerned that inflation is high and will remain outside of the target band for most of the year. The SARB is presented as unable or unwilling to support economic growth or the Rand regardless of how this impacts on consumers - an actor who, at least from these media representations, is largely missing from the SARB's discourse. This is countered by the financial experts whose discourse seems more sympathetic to consumers as they predict higher and more persistent inflation and tend to emphasise economic growth and the exchange rate in addition to inflation. That media narratives continuously emphasize the increase of prices fosters a sense of alarm. The world of consumers within these narratives consists of high and increasing prices - food, oil, clothing, water, and electricity to name but a few - in conjunction with weak economic growth and a range of local and international risks, which threaten to derail things further due to the inability or resistance of the SARB to contain inflation more firmly. 


\section{Implications}

Based on our analysis of inflation in South African newspapers, we identified four actor groups involved in inflation narratives - the SARB, financial experts, consumers and the media itself. Each of these actors have different models and levels of knowledge about the economy, which influences its presentation of inflation and the role of the SARB. There are at least three distinct dimensions that set these models apart. The first relates to the scope of inflation associated with each actor group. Representations of the SARB tend to emphasise a narrow view of inflation since the narratives emphasise the importance of core inflation (defined in a standardised fashion). From the SARB's perspective this is because the broader measure of inflation, namely headline inflation includes volatile components such as food, non-alcoholic beverages, petrol, and electricity. This focus is somewhat unsurprising given that core inflation is the component of price increases that central banks tend to emphasize as being most directly responsive to monetary policy, despite the fact that the mandate of the SARB refers to headline inflation. Commentary by financial experts, shows the use of a much wider range of inflationrelated concepts. In media reports they may comment on, for example, international inflation rates in the US or other emerging economies, or local inflation issues such as food price inflation, car inflation, household inflation, inflation forecasts, and so on. It is interesting to note the emphasis on currency movements, and economic growth (in addition to inflation) - a focus we discussed earlier in this article. It is true that economic growth and the exchange rate have an impact on inflation, so the SARB would not ignore these factors, but the SARB maintains that it is unable to simultaneously pursue these goals in their own right. This distinction is, however, not clearly explained, so this divergence of perceived priorities creates the impression that the SARB and the financial analysts in opposition to each other. 
Finally, the scope of inflation as presented in relation to consumers focuses primarily on the close association between inflation and the changes in the cost of living. We see this in the many references to the consumer price index as well as emphasis on the increase in prices of specific consumer goods and services such as a variety of food products, beverages, clothing, footwear, oil, petrol, electricity, and water. The fact that the SARB's publically announced numerical target is set in terms of the consumer price index, which is a cost of living index, is likely to reinforce this link. Where these three positions meet, we find an overlapping of a range of inflation concepts which are rarely defined or distinguished from one another. Only the exclusion based version of core inflation is ever explicitly defined. The constant reference to rising prices of consumer goods and services renders the index that excludes prices fora large share of consumer goods and services incongruent with the lived experience of consumers. This provides a rationale for central banks to explain what monetary policy can do to control inflation while at the same time remaining sensitive to lived experience of households.

The second dimension differentiating these actor groups relate to the persistence of inflation trends. As our analysis showed, the SARB appears confident that any rise in inflation is temporary and is expected to return to within the target range. Financial experts on the other hand, are often reported to present inflation as more persistent. Many analysts reported in the media make clear that inflation is categorically bad, not only because it is too high, but also because high or rising inflation may result in interest rate hikes, which are viewed as detrimental to economic growth. Finally, financial analysts often comment extensively on the relative price movements of some of the most volatile consumer goods, such as fuel and food, which creates the impression that prices are rising or expected to increase further, and that these increases are a persistent trend. This contrast between the views of the SARB and the 
financial analysts about the persistence of inflation may be further understood by considering different time horizons to which they are referring, which we turn to next.

The final dimension which differentiates these contrasting economic models relates to their use of different time horizons. The SARB is portrayed as being predominantly forward looking, focusing specifically on the forecast of inflation over an 18-24 month horizon. This makes sense since this is one of the defining characteristics of an inflation targeting strategy. This presentation of the horizon of the SARB by the media compares well with the mainstream view of monetary experts (both academics and central bankers) that the current policy stance of the SARB, as an inflation targeting central bank, is determined by how it expects economic activity to unfold in the medium term future. However, the SARB need not act unless the uncertainty in the outlook convinces the MPC to change the stance of monetary policy. So they may not respond to temporarily high inflation if they believe it will be within the target in the medium term, or if the SARB has recently made adjustments to the policy rate which still need time to have their full impact. In contrast, the analysis in this paper suggests that financial analysts are portrayed as looking both forward and backward in time as they provide their own forecasts of future inflation trends or critiques of the SARBs outlook on the one hand and draw inferences based on past events on the other. ${ }^{13}$ Our analysis showed that, in 2014, past performance often overweighed future expectations in that actual high inflation trumped the SARBs predicted future decline. In addition to looking both forward and backward, the time horizons used by the financial analysts differed from the SARB in that they also often comment on economic developments that are short term in nature rather than

\footnotetext{
13 Inflation targeting was designed to promote transparency in order to hold the central bank accountable to the public in precisely this manner.
} 
focusing predominantly on the medium term as the SARB does. This corresponds well with the earlier conclusion that financial analysts often focus on the exchange rate and economic growth in addition to inflation. For example, while inflation is high, elevated interest rates will dampen economic growth in the short term, but if inflation does recede back into the target range in the medium term then both of these trends are likely to reverse. In terms of time horizons, consumers occupy perhaps the most interesting space, being neither forward- nor backward-looking but focused instead on the immediate, short-term outcomes of increasing prices. This makes rising inflation and corresponding monetary policy a double-edged sword as the immediate impact of both inflation and an increase in interest rates are detrimental to them.

These divergent time horizons as well as differences in the conceptualization of the scope and persistence of inflation set the stage for newspaper narratives on inflation. To some degree, we find represented in the perspective of the SARB elements of the functionalist approach. Throughout 2014, the central bank maintains the same message: from a forward-looking and narrow focus on inflation concepts most aligned with monetary policy, inflation is not persistent and will return to within the target range. This is the strategic message aimed to elicit a desired response - to anchor the public's inflation expectations. The critical perspectives of the financial analysts mimic the modern approach. By including a wider scope of inflation concepts, presenting backward- as well as forward-looking positions, and frequently contradicting the central bank's prediction on the persistence of inflation, financial analysts position themselves as active political players engaged in a power play against the SARB's central message, often redefining the scope, direction, and potential outcomes associated with inflation. Representations of consumers are more consistent with the traditional approach. Their immediate focus on short-term outcomes, especially in relation to 
high inflation and the cost of living reflects the economic temperature of society, the inflationrelated ideas and values most salient to them.

At first glance, we might conclude that the media’s composition of these contrasting positions reflect a hybrid approach since the tensions created by this conflict serve the news processing machine’s obsession with creating marketable products. A more naïve interpretation may even conclude that these representations of inflation in the media represent Gans’ ideal of a modern multi-perspectival approach to news. While this may to some extent be true, these perspectives are not presented as alternative positions on the same issue. Instead of representing different actors within a network, we observe here a decomposition of a network, a fracturing of the old and new dimensions of media discourse into something else. Presented here are three different layers of society, each with their own sets of priorities, ambitions, and needs. Without resolving the conflict in favor of one position over the others, the media positions these competing versions in a way that seemingly coexist with one another. Based on our analysis of the print media in South Africa, we identified a media platform that has diversified its representations of societal actor groups in a way that simultaneously presents and serves different agendas. When reading a news report on inflation, each interest group - the central bank, financial analysts, and consumers -can selectively find something that partially addresses their interests and concerns. Thus, the decomposition of the network into competing, irreconcilable values and explanations of information concurrently serves different groups with incompatible interests. Our study therefore identifies a new approach in the media discourse, a late modern approach, in which the South African media aligns with a hybrid society and its struggle to make sense of hybrid socio-political and economic interests. We find that the South African media deals with this in a way that manages to concurrently serve multiple audiences with incompatible needs. 


\section{Conclusions}

This late modern approach to analyzing media content has significant impact on the role of inflation expectations. Central banks and academics have recognized that monetary policy is strategic in nature, and inflation targeting and increased levels of transparency have emerged in response to this. While monetary policy tends to be forward looking and current policy stances are determined by how the SARB expects economic activity to unfold in the future, the decomposition of the power network into diverging inflation narratives has implications on how inflation evolves over time. While anchoring inflation expectations is one of the SARB's primary tasks, our analysis highlights the risks for a central bank that emphasizes clarity and transparency as effective tools for communicating monetary policy aims to the public when the message is communicated via the media that need not share the same objectives. Although carefully crafting inflation messages are indeed important, this approach fails to recognize that the media serves multiple, incompatible interests, which ultimately may make the media an unreliable partner.

While our study is limited to an analysis of the message, that is, the actual news content and the way inflation and the SARB is presented in the media, our analysis indicates that the media does not attempt to further the central bank's aims. Regardless of the time and resources invested into carefully crafting appropriate messages, or of training journalists, the central bank's position will always be 4 . in competition with many other views presented in the media.

Furthermore, it is important to note that an educational or relatively detached position adopted by the central bank, whether in relation to the views of financial analysts or 
representatives of the public is likely to run the risk of making the SARB appear unaware of, or unsympathetic towards, the plight of the consumer. ${ }^{14}$

It is possible that the contrarian position often taken by financial analysts may offer direction for future communication strategies: Although analysts were presented as the most critical, their views tended to be aligned with public concerns, such as rising living costs, unemployment, and economic growth, which made these analysts seem attuned with the concerns of the public. Ironically, this alignment inadvertently positions SARB monetary policy not only against the advice of analysts but, more importantly, against the interests of the public. Thus, focusing on public interests as the outcome of SARB's monetary policy, in other words, casting its inflation policy and its communication strategies thereof in line with public interest may disconnect analysts with consumers and the public. If both the SARB and analysts speak in the language of a concerned and economically stressed public, the SARB may be able to provide a more effective counterweight to a relatively heterogeneous and uncoordinated set of opinions from analysts. The differential treatment of unemployment or price rises by the SARB and financial analysts as well as its significance to the South African context serves as a good example. Even though the SARB cannot address the structural economic factors that affect employment via monetary policy decisions, monetary policy decisions are viewed by the public as having an impact on employment. By addressing publicly fears and concerns over issues most salient to the public in a way that illustrates that monetary policy makers are not choosing to ignore these but rather are making choices that consider their options responsibly, this has the potential to increase the attention the media

\footnotetext{
${ }^{14}$ Many central banks appear to be aware of this. As a result, educational outreach in various forms has emerged as important vehicles increasingly being used to better inform the public. Of course, the aim is also partly in support not only of the principles of transparency but also to maintain public accountability thereby protecting their independence. Examples include the U.S. Federal Reserve, the Bank of Canada, and the Reserve Bank of New Zealand.
} 
and the public give to the views of the SARB. The challenges facing the SARB are similar to ones that are impacting central banks elsewhere in the aftermath of the financial crisis of 20089. Whereas prior to the crisis monetary authorities could focus public communication almost exclusively on inflation and aggregate economic conditions this is changing. Examples include former Fed Chair Janet Yellen's speeches on income inequality or ECB President Mario Draghi’s comments on Eurozone fiscal policy and governance.

We identify a few areas where there is a particular disconnect between the reported position of the SARB and those of the other actors. These include the different horizons on which the actors focus, and the role of the SARB with respect to how it should respond to exchange rate. Finally, the media is naturally interested in the real economic consequences of monetary policy and tends to over-simplify another trade-off, namely the one between inflation and economic growth or unemployment. The notion that being accountable for meeting an inflation objective is the best strategy to ensure that some of the conditions for solid economic growth are met is a position of the SARB that is not clearly conveyed by the media. This presents possibly the greatest communications challenge for a central bank like the SARB because structural economic factors that it cannot address via monetary policy decisions are outside its remit. In this case, how well the Treasury and the central bank jointly manage economic policy becomes the critical issue. The political economy implications of the role, functions and independence of the SARB are likely to play a secondary role in the day to day reporting of news about monetary policy, but an understanding of these remain crucial to an acceptance of the SARB's monetary policy decisions.

Ours, of course, is not the last word on the subject. Clearly, an analysis over a longer time span may provide additional insights about how central banks and the media communicate over a business cycle. Furthermore, the emergence of social media represents another avenue 
of communication differs markedly from the kind of sources considered in this study. Finally, it would be interesting to complement our findings with similar findings either for other emerging market or advanced economies to obtain a broader perspective on the impact of the media on how the work of monetary policy is interpreted. These extensions are left for future research.

\section{References}

Anderson, C. W., Bell, E., \& Shirky, C. 2012. Post industrial journalism: Adapting to the present. New York, NY: Tow Center for Digital Journalism, Columbia University.

AMPS, 2015. South African Advertising and Research Foundation. Accessed: June 2015. http://www.saarf.co.za/amps/readership.asp.

Bergman, M. M., 2010. Content Configuration Analysis. StudyCube. 35-48.

Bergman, M. M., Bergman, Z., 2011. Perspectives of learners and teachers on school dysfunctions in South Africa. Education as Change 15(1): 35-48.

Blinder, A. S., Wyplosz, C., 2004. Central Bank Talk: Committee Structure and Communication Policy. January 9, 2005.

Blinder, A. S., Ehrmann, M., Fratzscher, M., De Haan, J., Jansen, D., 2008. Central Bank Communication and Monetary Policy: A Survey of Theory and Evidence. Journal of Economic Literature 46(4): 910-945.

Bulír, A., Čihák, M., Jansen, D. J., 2013a. What Drives Clarity of Central Bank Communication About Inflation?. Open Economies Review 24(1): 125-145.

Bulír, A., Čihák, M., Šmídková, K., 2013b. Writing Clearly: The ECB's Monetary Policy Communication. German Economic Review 14(1): 50-72.

Bundesbank, D., 2000. Monetary Policy Transparency. Monthly Report 52(March): 15-30.

Cecchetti, S. G., 1998. Policy Rules And Targets: Framing The Central Banker's Problem. Federal Reserve Bank New York- Economic Policy Review 4(2): 1-14.

Croteau, D., \& Hoynes, W. 2007. The Media Industry: Structure, Strategy and Debates'. In Media Studies: Key Issues and Debates. SAGE.

Cukierman, A., 2009. The Limits of Transparency. Economic Notes 38: 1-37.

Della Vigna, S., Kaplan, E., 2007. The Fox News Effect: Media Bias and Voting. Quarterly Journal of Economics 112(3): $1187-1234$.

Della Vigna, S., Gentzkow, M., 2009. Persuasion: Empirical Evidence. The National Bureau of Economic Research. Working Paper no. 15298. 
Della Vigna, S., La Ferrara, E., 2016. Economic and Social Impacts of the Media.

Ehrmann, M., Fratzscher, M., 2007. Transparency, Disclosure and the Federal Reserve. International Journal of Central Banking 3(1): 179-225.

Eijffinger, S., van der Cruijsen, C., 2010. In: P.Siklos, Bohl, M. and Wohar, M. (Eds.).The Economic Impact of Central Bank Transparency: A Survey.Cambridge and New York: Cambridge University Press, 261-319.

Friedman, M., 1968. The Role of Monetary Policy. American Economic Review 58: 1-17.

Gans, H. J. 1970. Deciding What's News: A Study of CBS Evening News, NBC Nightly News, Newsweek, and Time ( 2 edition). Evanston, Ill: Northwestern University Press.

Gentzkow, M., Shapiro, J. M., 2010. What drives media slant? Evidence from U.S. daily newspapers. Econometrica 78(1): 35-71.

Gitlin, T. 1978. Media sociology: The dominant paradigm. In G. C. Wilhoit \& H. De Bock (Eds.), Mass communication review yearbook (Vol. 2, pp. 73-122). Beverly Hills, CA: Sage.

Goodhart, C. A. E., 2010. The changing role of central banks. Bank for International Settlements Working Paper No.326.

Gürkaynack, R., Sack, B., Swanson, E., 2005. The sensitivity of long-term interest rates to economic news: evidence and implications for macroeconomic models. American Economic Review 95(1): 425436.

Gürkaynack, R., Levin, A., Swanson, E., 2006. Does Inflation Targeting Anchor Long-Run Inflation Expectation? Evidence Form Long-Run Bond Yields in the U.S, U.K., and Sweden. Federal Reserve Bank of San Francisco Working Paper Series Working Paper 2006-09.

Haldane, A., 2000. Ghostbusting: The UK experience of inflation targeting. Washington.

Hamilton, J., 2004. All the News That's Fit to Sell. How the market transforms information into news.: Princeton University Press.

Herman, E. S., \& Chomsky, N. 1988. Manufacturing consent: the political economy of the mass media. Pantheon Books.

Jarvis, J. 2006, July 5. Networked journalism. Retrieved February 19, 2019, from https://buzzmachine.com/2006/07/05/networked-journalism/

Kydland, F., and Prescott, E., 1977. Rules Rather than Discretion: The Inconsistency of Optimal Plans. Journal of Political Economy 85(3): 473-492.

Lucas, R., 1976. Econometric policy evaluation: a critique. Amsterdam: North Holland.

Maier, P., 2010. 10. In: Pierre L. Siklos, M. T. B., Mark E. Wohar (Eds.).How Central Banks Take Decisions: An Analysis of Monetary Policy Meetings.New York: Cambridge University Press, 320-356.

Mankiw, G., and Reis, R., 2007. Sticky Information in General Equilibrium. Journal of the European Economic Association 5(2-3): 603-613. 
Mishkin, F. S., 1999. International Experiences with Different Monetary Policy Regimes. National Bureau of Economic Research Working Paper 7044.

Mishkin, F. S., 2004. In: Kent, C. and Guttmann, S. (Eds.).Can Central Bank transparency Go Too Far?RBA Annual Conference Volume: RBA, 48-66.

Poole, W., Rasche, R. H., 2003. The Impact of Changes in FOMC Disclosure Practices on the Transparency of Monetary Policy: Are Markets and the FOMC Better 'Synched'? Federal Reserve Bank of St. Louis Review 85(1): 1-10.

Reese, S. D. 2009. Managing the symbolic arena: The media sociology of Herbert Gans. In H Pöttker (Ed.) Öffentlichkeit als gesellschaftlicher Auftrag. Klassiker der Sozialwissenschaft über Journalismus und Medien (pp. 279-294). Hamburg: UVK.

Reese, S. D., \& Ballinger, J. 2001. The roots of a sociology of news: Remembering Mr. Gates and social control in the newsroom. Journalism \& Mass Communication Quarterly, 78(4), 641-658.

Reese, S. D., \& Shoemaker, P. J. 2016. A Media Sociology for the Networked Public Sphere: The Hierarchy of Influences Model. Mass Communication and Society, 19(4), 389-410. https://doi.org/10.1080/15205436.2016.1174268

Rose, A. K., 2007. A stable international monetary system emerges: inflation targeting is Bretton Woods, reversed. Journal of International Money and Finance 26 (2007) 663-681.

Ryfe, D. 2006. Guest editor's introduction: New institutionalism and the news. Political Communication, 23, 135-144.

Shelling, T. C., 1960. Strategy of Conflict. Cambridge, Ma.: Harvard University Press.

Siebert, A., 2006. Is Central Bank Transparency Desirable? . (5641).

Siklos, P. L., 2003. Assessing the Impact of Changes in Transparency and Accountability at the Bank of Canada. Canadian Public Policy 29: 279-299.

Sims, C., 2010. Rational Inattention and Monetary Economics Amsterdam: North-Holland.

Svensson, L. E. O., 1997. Inflation forecast targeting: Implementing and monitoring inflation targets. European Economic Review 41(6): 1111-1146.

Swank, O. H., Visser, B., 2007. Is Transparency to no avail? Committee Decision-making, Premeetings, and Credible Deals. Tinbergen Institute Discussion Papers 07-055/1.

Walsh, C. E., 2003. Cambridge: MIT Press.

Weber, M. 1910/2001, "Vorbericht über eine vorgeschlagene Erhebung über die Soziologie des Zeitungswesens", in Pöttker, H. (Ed.), Öffentlichkeit als gesellschaftlicher Auftrag. Klassiker der Sozialwissenschaft über Journalismus und Medien, UVK Universitätsverlag Konstanz, Konstanz, pp. 316-325.

Weimann, G., 1994. The Influentials: People who influence people. New York: State University of New York Press. 
Winkler, B., 2002. Which Kind of Transparency? On The Need for Effective Communication in Monetary Policy. Ifo Studien 48: 401-427. 